\title{
ESTABLISHMENT OF VICARIOUS CALIBRATION/VALIDATION FACILITY FOR SPACE BORNE HIGH AND MID RESOLUTION OPTICAL SENSORS
}

\author{
B.SanthiSree ${ }^{*}$, N.Raghavender ${ }^{1}$, K.S.Raju ${ }^{1}$, D.Chandrasekaran ${ }^{1}$, B.Gopala Krishna ${ }^{1}$, A.Senthil Kumar ${ }^{2}$ \\ ${ }^{1}$ National Remote Sensing Centre, Balanagar, Hyderabad-500037, Telangana, India, \\ (santhisree_b, raghavender_n, raju_ks, chandrasekharan_d, bgk) @nrsc.gov.in \\ ${ }^{2}$ Centre for Space Science and Technology Education in Asia and the Pacific, IIRS Campus, 4, Kalidas Road, Dehradun 248001, \\ India, cssteap@iirs.gov.in
}

\section{Commission V, SS: Emerging Trends in Remote Sensing}

KEY WORDS: Vicarious calibration, Absolute radiometric calibration, Calibration/Validation (Cal/Val) site, Shadnagar, LSF (Line Spread Function), MTF (Modulation Transfer Function)

\begin{abstract}
:
Vicarious calibration refers to methods that make use of "invariant" natural targets of the Earth for the post-launch calibration of sensors. This process of calibration is useful for initial phase orbit operation of sensor and thereafter for validation during its operational span. This method of periodic evaluation of radiometric and geometric performance of the space-borne optical sensors and validation of derived radiance/reflectance is to ensure availability of consistent and accurate data products to the user community. This paper describes one such Cal/Val facility's design, engineering aspects and realization at National Remote Sensing Centre (NRSC), Shadnagar. The target materials used for filling the Cal/Val site are studied for its reflectance. These targets have reflectance ranging from 9\% to 53\%, in the VNIR (Visible and Near Infra-Red) region. This paper also describes instruments used for calibration and homogeneity studies of targets for its invariance since operationalisation (January 2016). The last section of this paper is about reflectance based absolute radiometric calibration of medium resolution Indian Remote Sensing (IRS) sensor (Resourcesat and Cartosat series) using RT model and edge based LSF/MTF estimation of high resolution sensor carried out using the $\mathrm{Cal} / \mathrm{Val}$ facility.
\end{abstract}

\section{INTRODUCTION}

Periodic evaluation of radiometric and geometric performance of the space-borne optical sensors and validation of satellite derived radiance/reflectance of earth scenes using these sensors are becoming mandatory requirements to ensure availability of consistent and accurate data products to the user community. Moreover, the need for inter-operability of sensors to fill data gaps over different regions using data from multiple sensors calls for inter-sensor comparison between different space-borne sensors. It calls for using a unified scale of measurement thus bringing in traceability. Space-borne sensor, in-orbit calibration results will be more appropriate (Dinguirard et al, 1999) compared to the lab calibrations, as it is a combined effect of ground and atmospheric conditions. Natural sites internationally identified for $\mathrm{Cal} / \mathrm{Val}$ activities are mostly based on uniform deserts, dry lake beds/playas, large salt pans and snow features that are scattered across globe.

To cover wide dynamic range in a single experiment and also to address logistic problems involved in mobilising resources to conduct calibration experiments, an in-house calibration site was envisaged. The site is designed, successfully established and being operated at the NRSC of Indian Space Research Organisation (ISRO). The campus is located at Shadnagar, having geographical coordinates $17.03^{\circ} \mathrm{N}, 78.18^{\circ} \mathrm{E}$, which is about $60 \mathrm{~km}$ south of Hyderabad city, shown in Figure 1.

Calibration site is spread over an area covering $250 \mathrm{~m} * 250 \mathrm{~m}$ approximately. Majority (>96\%) of the total area is dedicated for large targets, to characterise large foot print sensors and the remaining for very high resolution sensors. Satellite sensors with spatial resolutions of $30 \mathrm{~m}$ or better can be characterised with the targets (i.e soils \& stones) available in larger area. Sensors of sub-metre spatial resolution can be characterised on the uniquely designed structure (Raghu Venkataraman et al, 2015) with paint targets.

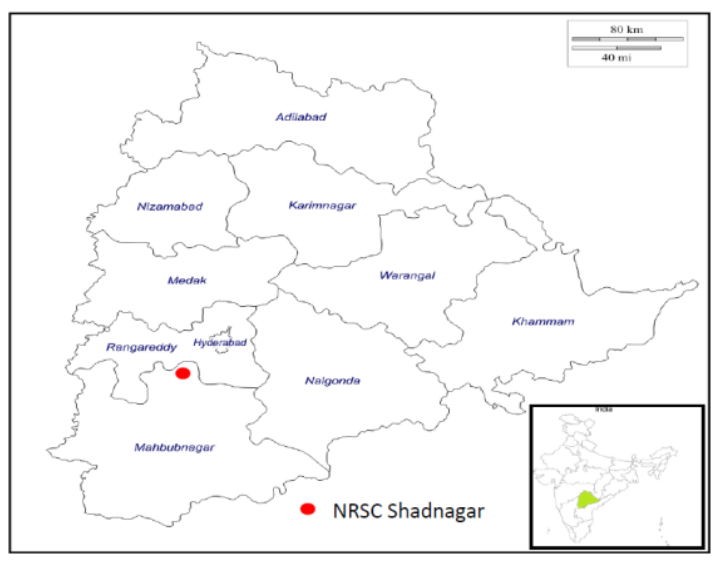

Figure 1. Location of NRSC Shadnagar campus on state map of Telangana

*Corresponding author: santhisree_b@nrsc.gov.in 


\section{SITE DESIGN AND ITS CHARACTERISTICS}

\subsection{Site design \& material selection}

Site was designed by considering parameters like sensor spatial resolution, different levels at which sensor to be characterised, availability of the area and maintainability of the site throughout all seasons/weather conditions. As the area required on the ground is directly proportional to the spatial resolution, large area is required for larger foot print sensors and smaller for smaller foot print sensors. Hence major area was dedicated to characterise satellite sensors and smaller for aerial sensors.

It is always better to have closely spaced intensity levels to characterise the sensor in its full dynamic range. However, practically it is very difficult to realise on the ground. Hence, it was decided to have five intensity levels covering low, mid and high levels. These five intensity levels were further realised by choosing naturally available materials to have long term stability and minimum maintenance. Size and position of the target material were fixed to cater sensor MTF estimation, radiometric characterisation and most importantly to avoid mixing of materials due to rain. The final site design layout is shown in Figure 2 and their dimensions are in Table 1. The site is established such that the orientation is 6degrees from north to aid edge based MTF estimation.

Target materials selected were basically of two types: Stone and soil. In stone, there are three varieties: Black shale stone (black colour), Granite gravel (grey colour) and white quartz (white colour). In soil, there are two varieties: black cotton soil (brownish black colour) and the local bare earth soil (red soil).

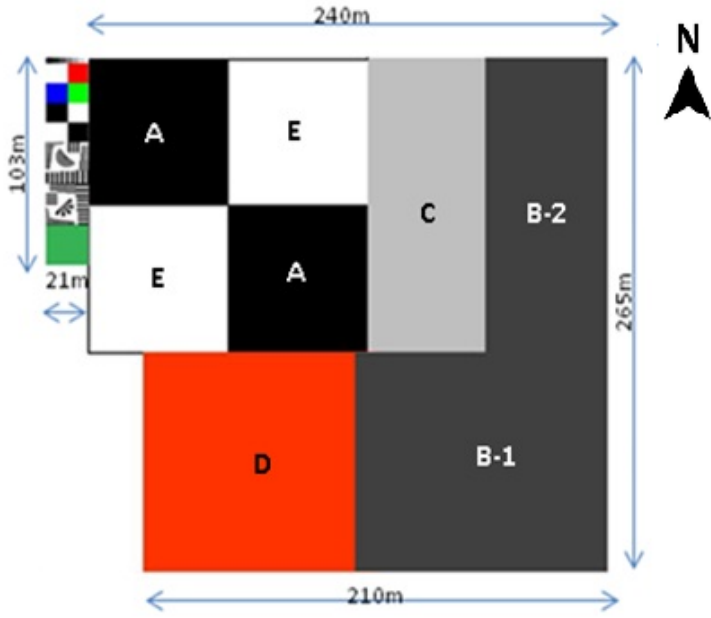

Figure 2. Final design layout of the calibration site. On the left hand side targets for very high resolution are also seen.

\subsection{Lab characterisation}

After selecting the type of materials to be deployed, the next crucial task was to understand their spectral characteristics. Material samples were received from different suppliers, having different sizes and colour combinations. Each sample was tested in the lab for its spectral response.

The lab test setup (refer Figure 3) primarily had a broad-band (Tungsten-Halogen) source and a spectro-radiometer. Sample was illuminated with the lamp source at $45 \mathrm{deg}$ and the response was measured in nadir direction. Responses of all the supplied samples were recorded. The material samples size between $1 \mathrm{~cm}$ to $2 \mathrm{~cm}$ and flat or near flat spectral response in $350-2500 \mathrm{~nm}$ wavelength region, were cleared for field deployment. Materials selected and their spectral responses are shown in Figure 4 and Figure 5. Out of five target materials, four (black stone, black soil, gravel and white stone) were bought locally and the red soil, is the native soil surface of the site.

\begin{tabular}{|c|c|c|c|}
\hline $\begin{array}{c}\text { Target } \\
\text { Material }\end{array}$ & $\begin{array}{c}\text { Reflectance } \\
(\%) \text { in NIR } \\
(\mathbf{0 . 7 7 - 0 . 8 6} \\
\boldsymbol{\mu m} \text { band }\end{array}$ & $\begin{array}{c}\text { Target } \\
\text { Size in } \\
\text { meters } \\
(\mathbf{L X W})\end{array}$ & $\begin{array}{c}\text { No. of } \\
\text { blocks }\end{array}$ \\
\hline $\begin{array}{c}\text { Black Stone } \\
(\text { A) }\end{array}$ & 9 & 70 X 70 & 02 \\
\hline $\begin{array}{c}\text { Black cotton } \\
\text { soil (B-1) }\end{array}$ & 12 & 125 X 105 & 01 \\
\hline $\begin{array}{c}\text { Black cotton } \\
\text { soil (B-2) }\end{array}$ & 12 & 140 X 50 & 01 \\
\hline $\begin{array}{c}\text { Grey } \\
\text { stone/Gravel } \\
(\mathrm{C})\end{array}$ & 18 & 140 X 50 & 01 \\
\hline Red Soil (D) & 29 & 125 X 105 & 01 \\
\hline $\begin{array}{c}\text { White Stone } \\
\text { (E) }\end{array}$ & 53 & $70 \times 70$ & 02 \\
\hline $\begin{array}{c}\text { Painted } \\
\text { concrete strip }\end{array}$ & ----- & 103 X21 & 01 \\
\hline
\end{tabular}

Table 1.Target dimensions

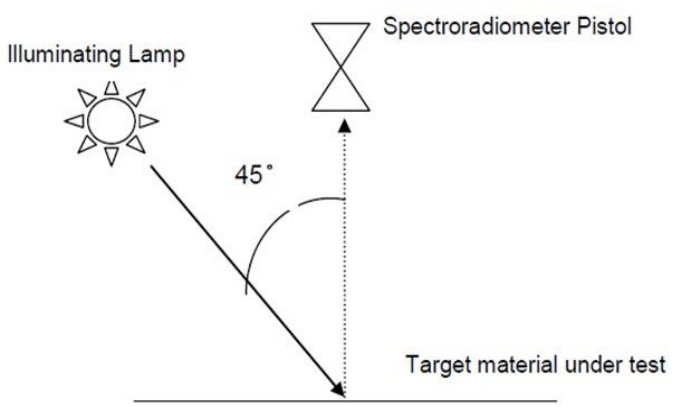

Figure 3. Laboratory setup
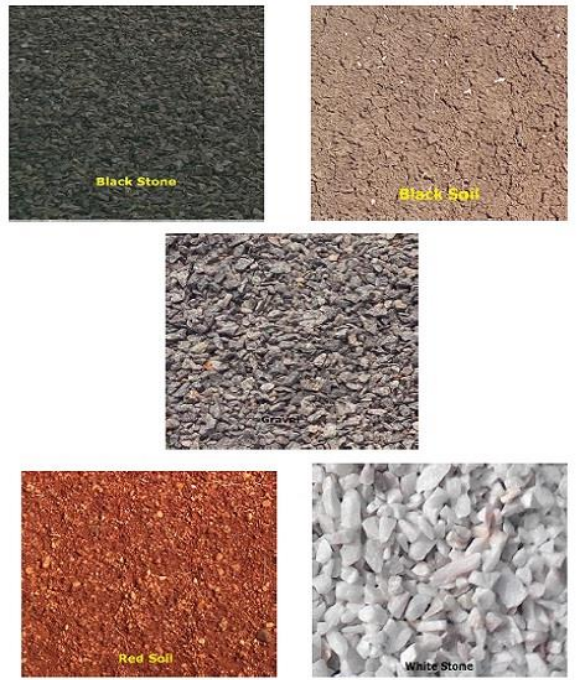

Figure 4. Five natural target materials. 


\subsection{Engineering \& Construction}

In this section, preparation of uniform base level surface (before laying target materials), sub soil drainage, construction of retain walls, filling of target materials are discussed.

The identified calibration site area (refer Figure 6) was having a slope of 7.0 meters one end to other end diagonally (refer Figure 7) i.e. $1 \mathrm{~m}$ gradient for every 50 meters. To develop the site uniformly, huge earth cutting as well as filling was required. With an average filling of $2.8 \mathrm{~m}$, phased manner filling and compaction with 10-12 tons road roller was done to attain good consolidation. Finally the base level surface is made to have $1 \mathrm{~m}$ gradient for every 100 meters at finished level. A sub soil drainage (refer Figure 8) network was also laid in the site, to arrest soil erosion due to rain water. Brick masonry peripheral walls were constructed around the site area to restore the filled target materials and in between the targets a bifurcation was made, with a brick wall of $5 \mathrm{~cm}$ thick to avoid mixing of materials (Figure 9).

Fully finished site as viewed by satellite in two different resolutions is shown in Figure 10

\section{GROUND TRUTH INSTRUMENTS AND SITE HOMOGENEITY}

\subsection{Ground truth instruments}

Calibration site should have associated instruments for measuring different in-situ parameters and systems for monitoring the performance of instruments as well. In-situ measurements include local weather, atmosphere, surface conditions and more related to the experiment being carried out.

The site is currently equipped with Automatic Weather Station (AWS), Sun Photometer, Ozone meter, Spectro-radiometer and GPS instruments for in-situ measurements. Instruments are shown in Figure 11.

The local meteorological conditions are being monitored using AWS measurements. AWS has 7 sensors, they are: wind speed (WS) \& wind direction (WD) sensor, air temperature (AT) \& relative humidity (RH) sensor, atmospheric pressure (AP) sensor global solar irradiation (GSI) sensor, soil temperature (ST) sensor at 7 levels, soil moisture (SM) sensor, rain gauge / precipitation (RG) sensor. AWS was supplied and installed by M/s Komoline Aerospace Ltd, Ahmedabad. Measurement records from each of the sensor are being continuously logged and analysed.

Sun-photometer is by M/s CIMEL Electronique, France, Model no: CE-318. This instrument measures AOD in 8 channels (340, $380,440,500,675,870,1020$ and 1640nm) and WV (using $940 \mathrm{~nm}$ channel).

Ozonometer is by M/s Solar Light Company, USA, Model no: 521. This instrument measures solar radiation in three channels $(300,305,312 \mathrm{~nm})$ to derive total ozone content in the atmosphere. Total water vapour content is derived based on $940 \mathrm{~nm}$ and $1020 \mathrm{~nm}$ measurements.

Spectro-radiometer is by M/s Spectra Vista Corporation (SVC), USA, Model no: HR-1024i. This instrument provides fine spectral radiance/irradiance measurements. Basically this spectro-radiometer has three individual linear detectors in
VNIR (350-1000nm), SWIR1 (1000-1885nm) and SWIR2 $(1885-2500 \mathrm{~nm})$ regions and no moving/scanning elements. Associated with three regions, it has three different spectral sampling intervals and spectral resolutions. However, by using interpolation technique, it is possible to have fine spectral profiles at $1 \mathrm{~nm}$ interval.

Garmin GPS-72H, is to plug-in the geographical coordinates, altitude values, correct universal time into the sun-photometer, ozonometer for a given time and location.

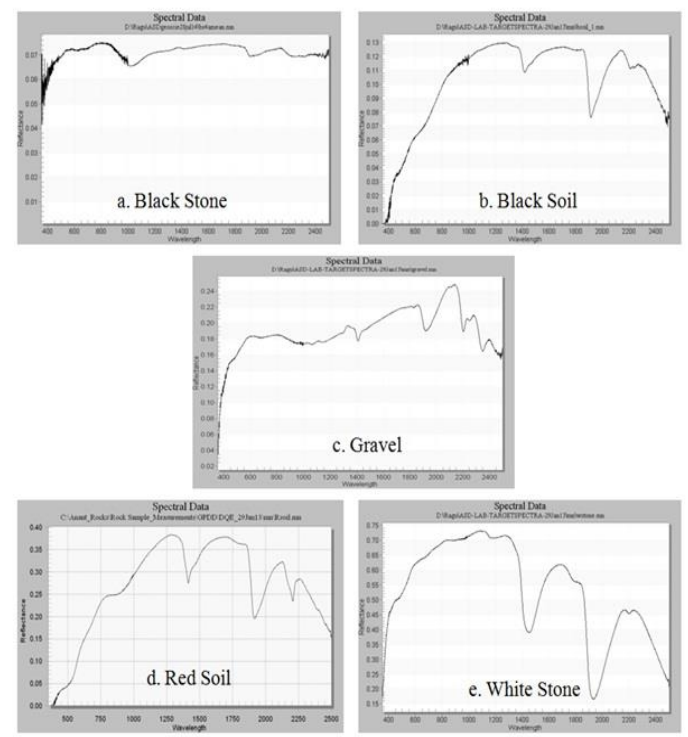

Figure 5. Spectral reflectance curves for five target materials

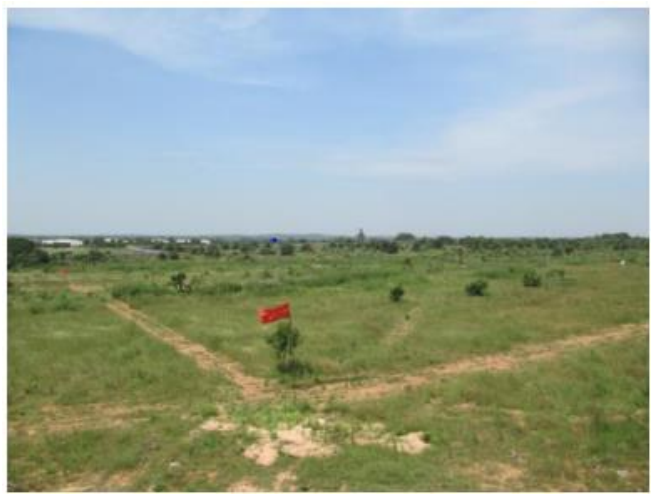

Figure 6. Site area before development.

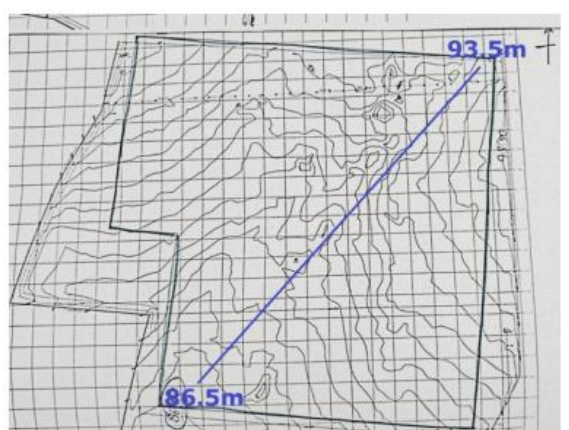

Figure 7. Terrain slope map before development 


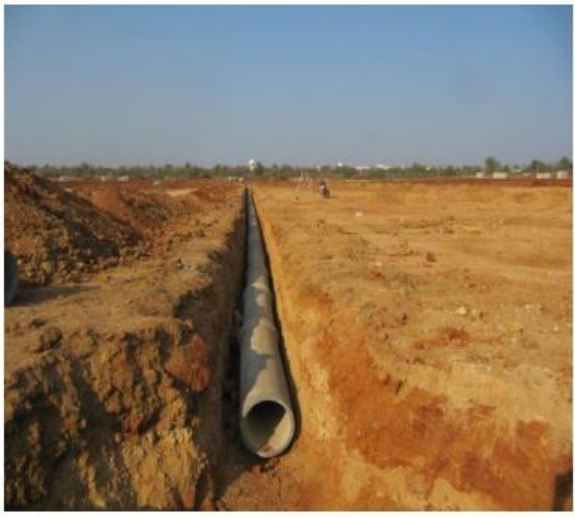

Figure 8. Sample image of sub soil drainage.

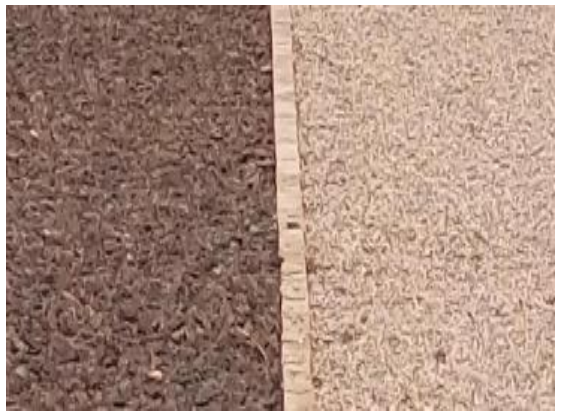

Figure 9. Bifurcation wall separating two materials.

\subsection{Homogeneity of Targets}

Invariance of the target spectral reflectance is very important to characterize on board sensors. In view of this, target spectral response was studied regularly from the date of site operationalisation, i.e, from January 2016. Variability found during January 2016 to March 2018 is presented here. Mean and dispersion values are found to be consistent and in acceptable limits. Statistical analysis was carried out in the spectral range 350-1800nm, because majority of the IRS sensors operate within this range. Target wise spectral reflectance is shown in Figure 12.

Black Stone: Mean reflectance for the study period in IRS bands B2 (520-590nm), B3 (620-680nm), B4 (770-860nm) and $\mathrm{B} 5(1500-1700 \mathrm{~nm})$ is $7 \%, 8 \%, 9 \%$ and $9 \%$ respectively. Maximum deviation is in the range of $0.7-0.9 \%$ for all the four bands.

Black Soil: Mean reflectance for the study period in IRS bands $\mathrm{B} 2, \mathrm{~B} 3, \mathrm{~B} 4$, and $\mathrm{B} 5$ is $7 \%, 8 \%, 12 \%$ and $17 \%$ respectively. Maximum deviation is in the range of $0.3-0.8 \%$ for all the four bands.

Gravel: Mean reflectance for the study period in IRS bands B2, $\mathrm{B} 3, \mathrm{~B} 4$, and $\mathrm{B} 5$ is $17 \%, 17 \%, 18 \%$ and $20 \%$ respectively. Maximum deviation is in the range of $0.4-1.1 \%$ for all the four bands.

Red Soil: Mean reflectance for the study period in IRS bands $\mathrm{B} 2, \mathrm{~B} 3, \mathrm{~B} 4$, and $\mathrm{B} 5$ is $12 \%, 21 \%, 29 \%$ and $43 \%$ respectively. Maximum deviation is in the range of $0.7-1.7 \%$ for all the four bands.

White Stone: Mean reflectance for the study period in IRS bands B2, B3, B4, and B5 is $45 \%, 49 \%, 53 \%$ and $55 \%$ respectively. Maximum deviation is in the range of $1.6-2.7 \%$ for all the four bands.
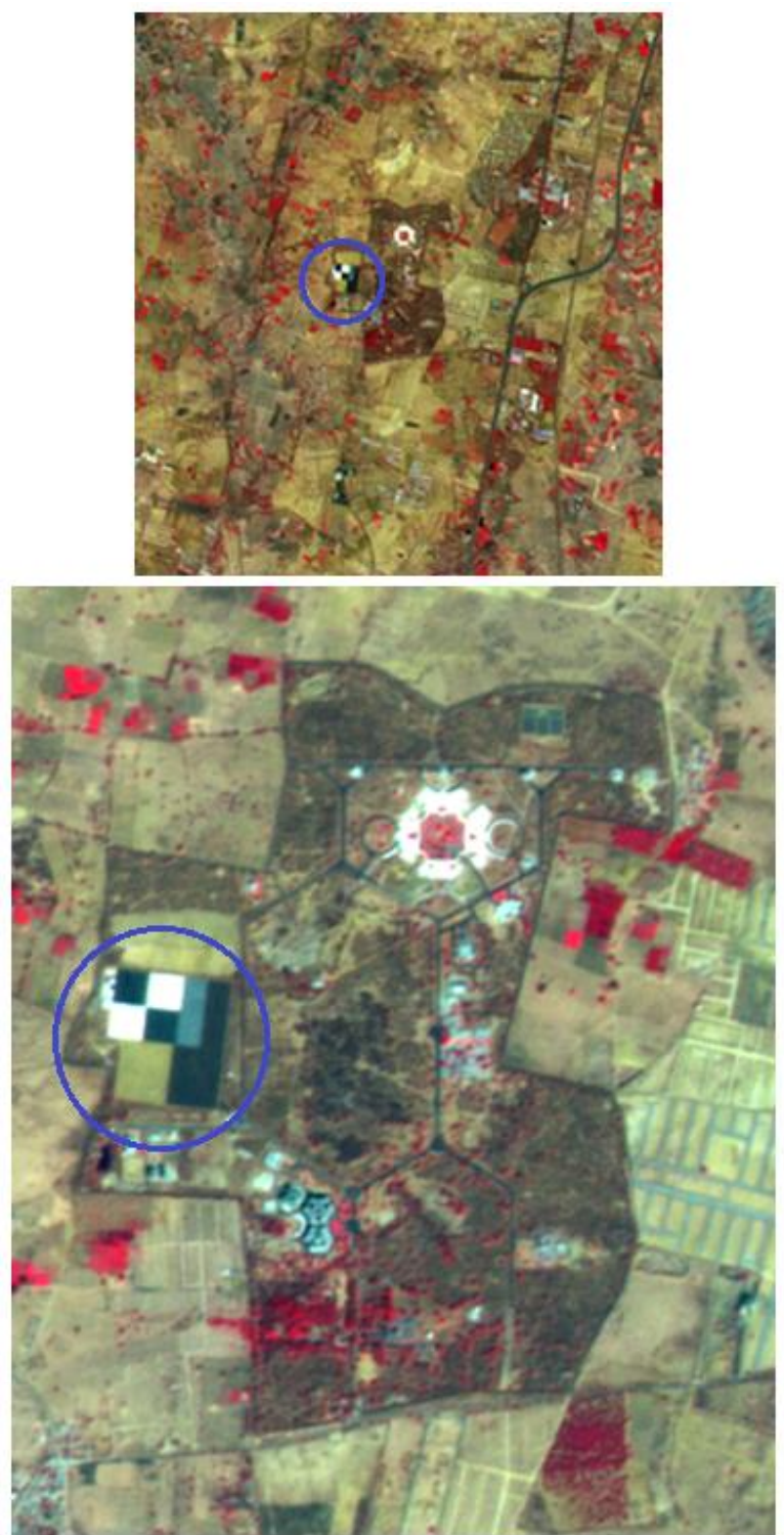

Figure 10. (Top) Calibration site (inside blue circle) as viewed by Resourcesat- 2 LISS-3 sensor at $24 \mathrm{~m}$ resolution; (Bottom) Site viewed by Resourcesat-2 LISS-4 sensor at $5 \mathrm{~m}$ resolution. Both images are in FCC combination.

\section{CALIBRATION EXPERIMENTS \& RESULTS}

Subsequent to the establishment of site, vicarious calibration experiments were planned and carried out synchronously with satellite overhead pass. IRS satellites having specific coverage pattern, cover the site at regular intervals of time. For example Resourcesat-2 (RS-2), LISS3 sensor, cover the site every 24 days. However, due to the limitation of clear sky conditions and monsoon season, the favourable period for experiments is between October to April only. As this paper is focusing on establishment of the facility, limited results obtained only are discussed. 


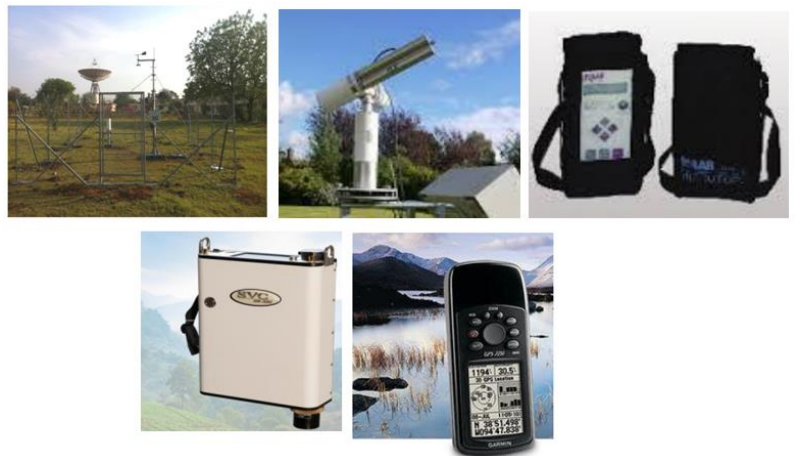

Figure 11. (Top row) AWS, Sun photometer, Ozonometer; (Bottom row): Spectro-radiometer and GPS.

\subsection{RS-2 LISS3 sensor vicarious calibration}

The process flow chart for absolute radiometric calibration (Slater et al, 1987; Biggar et al, 1994; Dinguirard et al, 1999; Thome, 2001) of a sensor followed is shown in Figure 13. In this method, the average surface reflectance of the target is computed and is weighted with Relative Spectral Response (RSR) curve to obtain band integrated surface reflectance. The band integrated surface reflectance, AOD, WV, O3, sun \& sensor angles were supplied to 6S RT code (Vermote et al, 2006) and the TOA (Top Of Atmosphere) radiance is determined. This radiance is generally termed as either simulated TOA radiance or predicted TOA radiance or simulated sensor radiance. Sensor measured radiance derived from the imagery is then compared with predicted TOA radiance to generate calibration coefficients (gain $\&$ offsets).

List of experiment dates and the atmospheric parameters for RS-2, LISS3 sensor are tabulated in Table 2. Six dates were selected in two years period covering summer \& winter seasons for generating the calibration coefficients of the sensor. Coefficients were generated based on the responses from Black and Red soil targets only. LISS3 sensor being mid resolution only these targets provide pure pixels in the imagery.

By following the procedure as specified above, band wise calibration coefficients were generated for LISS3 sensor. Newly generated coefficients along with the old coefficients are tabulated in Table 3 (Raghavender et al, 2017). Accurate radiances (better than $5 \%$ ) can be obtained by using these coefficients in conjunction with image DNs.

\subsection{Edge based LSF \& MTF estimation}

High contrast edges formed between black and white stone targets are basis for the estimation of LSF \& MTF of the sensor under study (Kohm, 2004.). Length of this high contrast slant edge is $70 \mathrm{~m}$, with which estimations can be made for sensors with spatial resolutions better than $8 \mathrm{~m}$. Estimations are also possible with other contrast edges; however obtained contrast will be lesser to that of black \& white edges. Process steps involved in the estimation are shown in Figure 14

LSF, MTF values were estimated for high resolution PAN (panchromatic) sensor of spatial resolution better than $1 \mathrm{~m}$. Calibration site image is shown in Figure 15. Estimated values in along, across track directions are tabulated in Table 4.
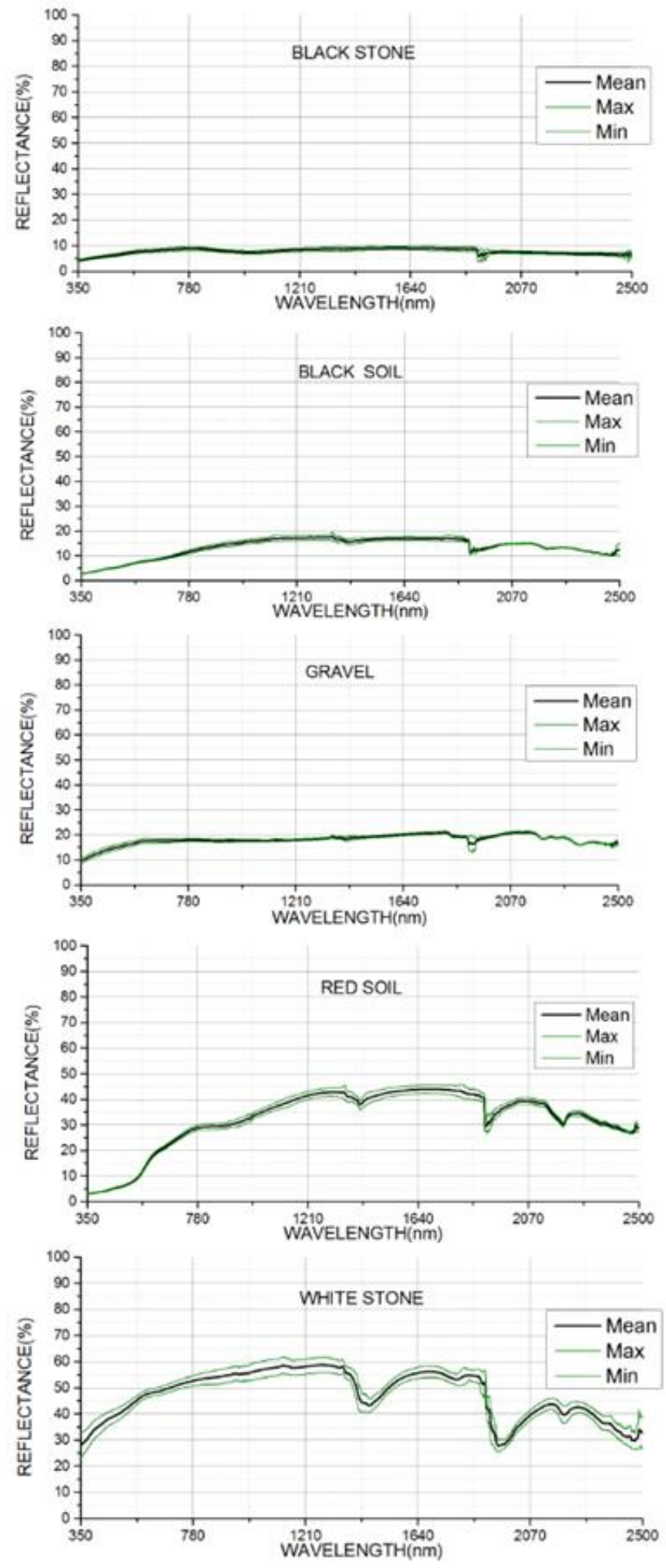

Figure 12. Spectral reflectance of all five targets from Jan2016 to Mar2018 


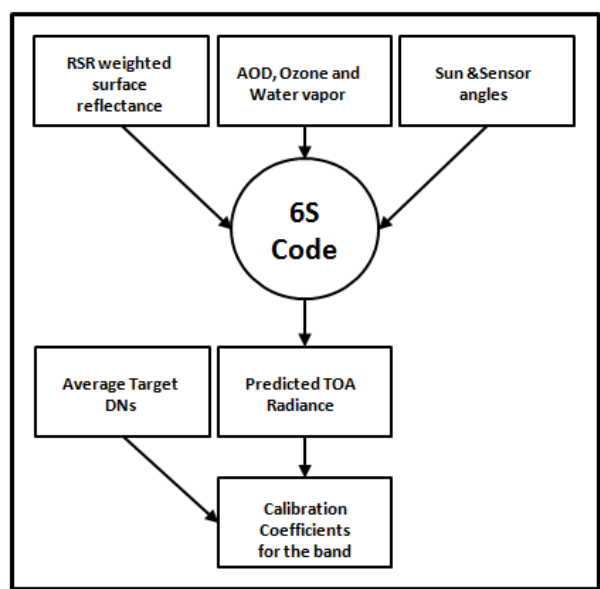

Figure 13. Reflectance based absolute radiometric calibration flow chart.

\begin{tabular}{|l|l|l|l|}
\hline $\begin{array}{l}\text { Experiment } \\
\text { date }\end{array}$ & $\begin{array}{l}\text { Mean } \\
\text { AOD at } \\
\text { 550nm }\end{array}$ & $\begin{array}{l}\text { Mean } \\
\text { Ozone } \\
\text { (DU) }\end{array}$ & $\begin{array}{l}\text { Mean } \\
\text { Water } \\
\text { vapor }(\mathbf{c m})\end{array}$ \\
\hline 28-Jan-15 & 0.203 & 265.91 & 0.68 \\
\hline 12-Nov-15 & 0.577 & 316.44 & 1.65 \\
\hline 16-Feb-16 & 0.317 & 245.76 & 1.24 \\
\hline 22-May-16 & 0.348 & 296.60 & 1.50 \\
\hline 10-Feb-17 & 0.566 & 286.00 & 1.00 \\
\hline 30-Mar-17 & 0.603 & 328.34 & 1.09 \\
\hline
\end{tabular}

Table 2. List of experiment dates for Resourcesat-2 (RS-2)

LISS 3 calibration and corresponding atmospheric parameters.

\begin{tabular}{|l|l|l|l|l|}
\hline $\begin{array}{l}\text { RS-2 } \\
\text { LISS-3 } \\
\text { Bands }\end{array}$ & Gain $_{\text {new }}$ & Offset $_{\text {new }}$ & Gain $_{\text {old }}$ & Offset $_{\text {old }}$ \\
\hline B2 & 0.0664 & -1.0729 & 0.0508 & 0 \\
\hline B3 & 0.0584 & -0.7321 & 0.0459 & 0 \\
\hline B4 & 0.0371 & -0.5705 & 0.0308 & 0 \\
\hline B5 & 0.0120 & -0.2119 & 0.0073 & 0 \\
\hline
\end{tabular}

Table 3.New and old gain $\&$ offsets.

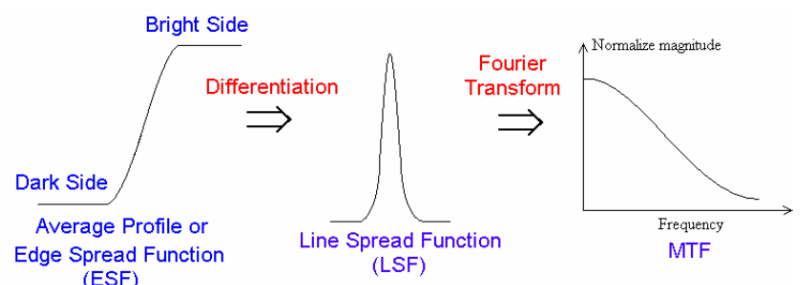

Figure 14. LSF \& MTF estimation process from slant edges (Courtesy: Dennis Helder, Choi ).

\begin{tabular}{|l|c|c|c|c|}
\hline \multirow{2}{*}{ Sensor } & \multicolumn{2}{|c|}{ LSF (pix) } & \multicolumn{2}{c|}{ MTF (\%) } \\
\cline { 2 - 5 } & Along & Across & Along & Across \\
\hline $\begin{array}{l}\text { C2S-PAN } \\
\text { (Date of pass } \\
\text { 12-01-2017) }\end{array}$ & 1.7 & 1.5 & 10 & 16 \\
\hline
\end{tabular}

Table 4.Edge based LSF \& MTF values for C2X-PAN sensor.

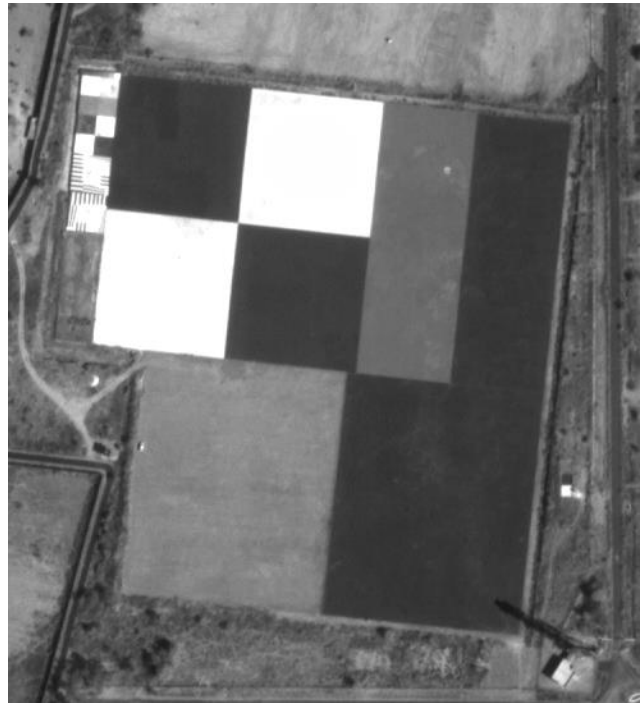

Figure 15. High contrast (Black \& White) edges in panchromatic imagery of high resolution sensor for MTF estimation.

\section{CONCLUSIONS}

$\mathrm{Cal} /$ Val site was designed, developed, and successfully operationalised in 2016. All the five natural targets were found to be stable, in terms of spectral response for last 3 years. Targets present in the site were efficiently used for the characterisation \& monitoring of in-orbit IRS sensors.

In the present work, absolute radiometric accuracy was arrived and radiometric calibration coefficients were computed for the mid-resolution $(23 \mathrm{~m})$ sensor, using two soil targets (Black \& Redsoil) in the VNIR and SWIR spectral channels. Radiometric characterization of high resolution multispectral sensor (with spatial resolution $1.6 \mathrm{~m}$ and $5 \mathrm{~m}$ ) was carried out using all the targets (five) present in the site.

C2S PAN MTF is computed effectively using the slant edge formed between black \& white stones. MTF of any high resolution sensor better than $8 \mathrm{~m}$ can be estimated in two directions using this facility.

\section{ACKNOWLEDGEMENTS}

The authors especially thank Sri Santanu Chowdhary, Director, NRSC, Dr. V.K. Dhadhval and Dr. Y.V.N. Krishna Murthy Former Directors, NRSC for their technical guidance and support.

We would also like to thank Dr. A.S.Kiran Kumar, former Chairman, ISRO for the encouragement and guidance while establishing this facility.

Authors would also like to thank Construction \& Maintenance Group (CMG), NRSC, for the civil engineering support in the facility development. 


\section{REFERENCES}

Biggar, S. F., Slater, P. N., and Gellman, D. I., 1994. Uncertainties in the in-flight calibration of sensors with reference to measured ground sites in the 0.4 to $1.1 \mathrm{~mm}$ range. In: Remote Sensing of Environment, 48:245-252.

Dinguirard, M., Slater, P.N. (1999), Calibration of SpaceMultispectral Imaging Sensors: A Review. In: Remote Sensing of Environment, 68:194-205.

Kohm, K. 2004. Modulation Transfer Function Measurement Method and Results For The Orbview-3 Higher Resolution Imaging Satellite. In: Technical Commission 1, XXth ISPRS Congress, 12-23, July.

Raghu Venkataraman,V., Abhijit,p. \& Anantha Padmanabha, E., 2015. A Unified Multi-Purpose Calibration Site for Aerial and High Resolution Satellite Sensors, In: Journal of The Indian Society of Remote Sensing, 43(1), pp. 37-43.

Raghavender, N., Santhi Sree, B., Raju, K.S., Chandrasekaran, D., Gopala Krishna, B., 2017. Estimation of radiometric calibration coefficients for Resourcesat-2 (RS-2) LISS-3 sensor using ground based targets. In: The $38^{\text {th }}$ Asian Conference of Remote Sensing (ACRS), New Delhi 2017.

Slater, P. N., Biggar, S. F., Holm, R. G., 1987. Reflectance and radiance based methods for the in-flight absolute calibration of multispectral sensors. In: Remote Sensing of Environment, 22:11-37.

Thome, K. J., 2001. Absolute radiometric calibration of Landsat 7 ETM+ using the reflectance-based method. In: Remote Sensing of Environment, 78:27-38.

Vermote, E., Tanre, D., Deuze, J. L., Herman, M., and Morcrette, J. J., and Kotchenova, S.Y., 2006. Second Simulation of the Satellite Signal in the Solar Spectrum-Vector (6SV). In: 6S User Guide Version 3, Department of Geography, University of Maryland, USA. 